Theodore H. Stanley MD, Simon de Lange MB BS FFARCs

\title{
The effect of popula- tion habits on side effects and narcotic requirements during high-dose fentanyl anaesthesia
}

\begin{abstract}
We measured and compared the anaesthetic requirements, incidences of chest wall rigidity and intraoperative hypertension, and time for recovery from anaesthesia after high dose fentanyl-oxygen anaesthesio in patients with and without histories of smoking, alcoholic intake and caffeine consumption who were undergoing coronary artery bypass grafting operations. Patients without a history of smoking and alcohol or caffeine intake required less fentany! for induction and maintenance of anaesthesia and experienced less chest wall rigidity and hypertension than similar patients who had been chronically exposed to andlor consumed these agents. Pretreatment with more pancuronium ( 1.5 us $1.0 \mathrm{mg} / 70 \mathrm{~kg}$ ) prior to ancesthesic induction and increased fentanyl ( $3 \times$ us $/ \times$ the "sieep" dose) administered after anaesthetic induction but before incision reduced the incidences of chest wall rigidity and intraoperative hypertension in patients
\end{abstract}

\section{Key words}

ANAESTHESIA: cardiovascular; ANAESTHETICS, INTRAVENOUS: fentanyl; BLOOD PRESSURE: drug effects, hypertension; suRGERY: coronary artery bypass grafting operations.

From the Department of Anaesthesiology, The University of Utah School of Medicine, Salt Lake City, Utah; and The University of Leiden Hospital, Leiden, The Netherlands.

Address correspondence to: Theodore H. Stanley MD, Department of Anesthesiology, The University of Utah School of Medicine, 50 North Medical Drive, Salt Lake City, Utah 84132.

Supported in part by Stanley Research Foundation, Salt Lake City, Utah. with positive histories of exposure to the agents to values similar to patienss without histories of exposure. Our findings suggest that population habits may affect the incidence of undesirable side effects during high dose fentanyl anaesthesia but that modifications in anaesthetic techique can minimize or eliminate these problems.

Large doses of fentanyl plus oxygen have been reported to produce analgesia, amnesia, stable cardiovascular dynamics and a minimum of problems in patients undergoing open-heart operations. ${ }^{1-6}$ However, some investigators have reported chest wall rigidity on anaesthestic induction, ${ }^{7-9}$ tachycardia during tracheal intubation, ${ }^{8,9}$ hypertension during and/or after tracheal intubation, stemotomy or cardiopulmonary bypass ${ }^{3,8,10,11}$ and intraoperative awareness $8,12,13$ with this technique. These findings were not reported in the original studies with anaesthetic doses of fentanyl. ${ }^{1.2}$ An explanation for the variance in these reports could be related to differences in population habits. This study was undertaken to determine if patients with differences in certain habits have different fentanyl anaesthetic requirements for induction and maintenance of anaesthesia and, as a result, if these differences are not recognized, a higher incidence of undesirable side effects.

\section{Methods}

The protocol was approved by the Universities of Utah and Leiden Human Experimentation Committees. Informed consent was obtained from each patient at the time of the preoperative visit.

Sixty patients with severe coronary artery disease 
scheduled for coronary artery bypass grafting (CABG) operations who were not taking beta or calcium channel blocking drugs, digitalis preparations, barbiturates or benzodiazepine compounds were divided into three equal groups (groups I-III) of 20 patients. Differences between groups related to the technique of anaesthetic induction and the patient's history of smoking, alcoholic intake and caffeine (coffee and tea) consumption. Patients in Group 1 had never smoked, denied ever consuming alcohol, coffee or tea and were taking only an oral vasodilator (nitroglycerin, isiscrbide dinitrate or isoxsupine hydrochloride) and/or a diuretic (hydrochlorthiazide) as cardiac medications. Patients in Groups II and III all smoked at least two packs of cigarettes/day for ten or more years, consumed at least two cups of coffee and/or tea/day, and drank 1-3 ounces of alcohol a minimum of three times/ week for at least ten years. Patients in Groups II and III also took an oral vasodilator and/or a diuretic as their only cardiac medications.

Patients were first considered for inclusion in the study at the preanaesthetic interview. Patients fulfilling the criteria for Group I were allocated to that group, while those fulfilling criteria for inclusion in Groups II and III were randomly placed in one of these groups. Patients not fulfilling criteria for inclusion in any of the groups were premedicated, randomly assigned, anaesthetized and had data recorded as patients in Groups I-III. This procedure was followed in an attempt to minimize bias in blinded clinician-investigators who, in the interest of optimal patient care, had access to the patients' charts. None of the data obtained from patients not assigned to Groups I-III were included in the statistical analysis. The study was simultaneously performed in Salt Lake City, Utah and Leiden, The Netherlands. An attempt was made to enter similar numbers of patients in each group at the same frequency in both hospitals.

All patients were premedicated with diazepam $(1.2 \mathrm{mg} / 10 \mathrm{~g}, \mathrm{IM})$ and atropine $(0.1 \mathrm{mg} / 15 \mathrm{~kg}, \mathrm{IM})$ 90 minutes prior to the scheduled time of operation. Upon arrival in the anaesthetic induction room, catheters were placed in a hand vein and a radial artery, a bipolar lead II electrocardiogram was continuously recorded, and a quadruple lumen Edwards pulmonary artery catheter was placed in the pulmonary artery. Cardiac output was measured in duplicate utilizing a thermodilution technique.
Following preparatory procedures and a tenminute stabilization period, control cardiovascular data, including systolic and diastolic arterial blood pressures, heart rate, cardiac output and right atrial and pulmonary capillary wedge pressures were recorded and the patients given oxygen to breathe. Two minutes later pancuronium $(1 \mathrm{mg} / 70 \mathrm{~kg}$ in Groups I and II and $1.5 \mathrm{mg} / 70 \mathrm{~kg}$ in Group III) was administered intravenously. Three minutes after pancuronium, fentanyl was administered at a rate of $400 \mu \mathrm{g} \cdot \mathrm{min}^{-1}$ intravenously by an investigator who was not blinded to the identity of the patient's group. Respiration was first spontaneous, then assisted and finally controlled, using a face mask and semi-closed system to maintain continously recorded end tidal $\mathrm{PCO}_{2}{ }^{*}$ and/or $\mathrm{PaCO}_{2}$ (as measured in radial arterial blood every $15-45$ minutes) at 32-40 torr. During infusion of fentanyl, patients were commanded to open their eyes and take a deep breath every five to ten seconds by an investigator who was "blinded" to the identity of the patient's group. Failure to respond to three consecutive commands was equated (by the blinded investigator) with unconsciousness. When unconscious, the patients were paralyzed with intravenous succinylcholine $\left(1.5 \mathrm{mg} \cdot \mathrm{kg}^{-1}\right)$ and had their tracheas intubated with a cuffed endotracheal tube. Patients were reparalyzed with pancuronium $\left(0.08 \mathrm{mg} \cdot \mathrm{kg}^{-1}\right.$ slowly, intravenously) 15 minutes after anaesthetic induction. Paralysis was maintained with $0.02-$ $0.04 \mathrm{mg} \cdot \mathrm{kg}^{-1}$ increments of pancuronium every 45-60 minutes until the end of cardiopulmonary bypass. After intubation, an amount of fentanyl equal to the dose producing unconsciousness was infused over the next 30 minutes in Groups I and II. $\dagger$ In Group III patients, three times the dose of fentanyl producing unconsciousness was infused over the next 30 minutes. $t$

Following completion of the fentanyl injection

*End tidal $\mathrm{PCO}_{2}$ measurements were not available at the University of Utah during the time the study was being periormed.

†This dose of fentanyl was administered by the unblinded investigator and was not revealed to the blinded clinician-investigator. The latter gave all subsequent fentanyl administered during the operation, decided when supplements were required in addition to fentanyl (according to criteria outlined above) and administered these supplements. 
the operation began. Additional fentanyl (in $250 \mu \mathrm{g}$ doses) was given intravenously throughout the operation whenever arterial blood pressure increased more than 15 per cent of preanaesthetic (control) values or patients showed signs of inadequate anaesthesia (movement, sweating, flushing, tearing or pupillary dilation). When three successive supplemental doses of fentanyl failed to decrease systolic or mean arterial blood pressures to within 15 per cent of control values within five minutes before or during bypass, the patients were given phentolamine (in 1-3 mg divided doses) until blood pressure decreased to control values. After bypass, $\mathrm{N}_{2} \mathrm{O}$ ( 50 per cent) was added to the inspired mixture of gases to treat hypertension not responding to supplemental doses of fentanyl. If $\mathrm{N}_{2} \mathrm{O}$ was ineffective in decreasing post-bypass hypertension to within 15 per cent of control systolic arterial blood pressure within ten minutes, a sodium nitroprusside infusion $\left(0.5-2.0 \mu \mathrm{g}^{\circ} \mathrm{kg}^{-1} \mathrm{~min}^{-1}\right)$ was started. The incidences of increases in systolic arterial blood pressure above 20 per cent of preanaesthetic (control) values during tracheal intubation, chest incision, sternotomy and maximal sternal spread were recorded for all groups.

A saline glucose solution (4.5 per cent glucose and 0.1 per cent normal saline) or Ringer's lactate was administered at a rate of $1000 \mathrm{ml} \cdot \mathrm{hr}^{-1}$ during prcanaesthetic preparations and $200-250 \mathrm{mg} \cdot \mathrm{hr}^{-1}$ throughout the remainder of the operation. The extracorporeal system was primed with Ringer's lactate solution $(1500 \mathrm{ml})$, glucose five per cent in water $(500 \mathrm{ml})$ and $500 \mathrm{ml}$ of a solution containing $100 \mathrm{mg}$ of albumin and 500 units of heparin. Patients were cooled to $26-28^{\circ} \mathrm{C}$ during extracorporeal support and rewarmed to $37^{\circ} \mathrm{C}$ at its conclusion.

Cardiovascular dynamics were recorded before anaesthetic induction (control), at the time the patients became unconscious, one minute after intubation, immediately before and five minutes after chest incision, before sternotomy and five and ten minutes after sternal spread.

The presence of muscle rigidity during anaesthetic induction was evaluated by the following scoring system: none $=$ no difficulty with ventilation and no clinical evidence of abdominal wall (as determined by palpation) or upper limb stiffness (as determined by manual elbow flexion); mild = can ventilate but with some difficulty associated with mild abdominal wall and/or upper limb stiffness; severe $=$ virtually impossible to mechanically ventilate prior to succinylcholine administration associated with marked abdominal wall, face, neck and upper limb stiffness.

Patients were all electively mechanically ventilated until the morning after surgery. During the first ten postoperative hours they were evaluated for return of consciousness every 15 minutes. Patients were considered conscious when they could give correct affirmative or negative responses to three consecutive questions. Once conscious, their ability to sustain adequate spontaneous respiration when taken off the ventilator was determined every 30 minutes. Patients were not considered ready for extubation until they had stable cardiovascular dynamics for two hours and were without evidence of neuromuscular blockade (via twitch and tetanus evaluation). Following this, extubation was considered possible if patients could maintain at least eight to ten breaths/min, could generate a negative inspiratory pressure of 20 tor and could sustain a $\mathrm{PaCO}_{2}$ of less than 45 torr and $\mathrm{PaO}_{2}$ of 100 torr or more while spontaneously breathing (without verbal encouragement) 40 per cent oxygen via a $T$ piece apparatus for 20 minutes.* All patients were interviewed 48 hours postoperatively. Questions were specifically directed at determining the presence or absence of pain during operation and memory of laryngoscopy, tracheal intubation or any aspect of the operative procedure.

Data were analyzed for statistical significance using Student's paired and unpaired t-tests, the unpaired t-test with Bonferoni modification, analysis of variance, analysis of variance with Bonferoni modification and the Chi-square test.

\section{Results}

The study was simultaneously performed over a 30-month interval (1979-1982) in Salt Lake City, Utah and Leiden, The Netherlands. Thirty-two patients (Group I $=11$, Group II $=11$, and Group $\mathrm{III}=10$ ) were entered into the study in Leiden and $28($ Group I $=9$, Group II $=9$, and Group III $=10)$

*Patients were not, in fact, extubated until the morning after surgery because of intensive care protocol. To facilitate mechanical ventilation after our test period, sedatives and/or analgesics were administered throughout the night as deemed necessary for patient comfort. 
TABLE \ Demographic and preoperative haemodynamic data (Mean \pm SD)

\begin{tabular}{|c|c|c|c|c|c|c|}
\hline & \multicolumn{2}{|l|}{ Group I } & \multicolumn{2}{|l|}{ Group II } & \multicolumn{2}{|l|}{ Group III } \\
\hline & Leiden & Sale Lake & Leiden & Salt Lake & Leiden & Salt Lake \\
\hline Number of patients & 11 & 9 & 11 & 9 & 10 & 10 \\
\hline Age (yeurs) & $50 \pm 6$ & $48 \pm 7$ & $51 \pm 5$ & $52 \pm 6$ & $50 \pm 7$ & $50 \pm 4$ \\
\hline Weight (kg) & $72 \pm 5$ & $69 \pm 5$ & $73 \pm 7$ & $72 \pm 7$ & $70 \pm 5$ & $74 \pm 8$ \\
\hline \multicolumn{7}{|l|}{ Heart rate } \\
\hline (beats/min) & $75 \pm 9$ & $72 \pm 7$ & $73 \pm 8$ & $69 \pm 8$ & $69 \pm 7$ & $73 \pm 7$ \\
\hline $\begin{array}{l}\text { Systolic arterial } \\
\text { blood pressure }\end{array}$ & & & & & & \\
\hline$(t o r)$ & $120 \pm 13$ & $124 \pm 9$ & $128 \pm 6$ & $123 \pm 8$ & $127 \pm 9$ & $128 \pm 11$ \\
\hline $\begin{array}{l}\text { Cardiac output } \\
\text { (U/min) }\end{array}$ & $5.1 \pm 0.9$ & $5.3 \pm 0.7$ & $4.9 \pm 0.6$ & $5.0 \pm 0.5$ & $5.1 \pm 0.6$ & $5.4 \pm 0.7$ \\
\hline $\begin{array}{l}\text { Right atrial pressure } \\
\text { (torr) }\end{array}$ & $9 \pm 1$ & $9 \pm 1$ & $8 \pm 1$ & $9 \pm 1$ & $9 \pm 1$ & $10 \pm 2$ \\
\hline $\begin{array}{l}\text { Pulmonary capillary } \\
\text { wedge pressure } \\
\text { (torr) }\end{array}$ & $8 \pm 2$ & $9 \pm 2$ & $7 \pm 2$ & $g \pm 2$ & $7 \pm 2$ & $7 \pm 1$ \\
\hline
\end{tabular}

TABLE II Cumulative doses of fertanyl $\left(\mu \mathrm{g} \cdot \mathrm{kg}^{-1}\right.$, Mean \pm SD)

\begin{tabular}{|c|c|c|c|c|c|c|}
\hline & \multirow[b]{2}{*}{ Unconscious } & \multirow[b]{2}{*}{ Incision } & \multirow{2}{*}{$\begin{array}{l}\text { Sternal } \\
\text { split }\end{array}$} & \multicolumn{2}{|l|}{ Bypass } & \multirow{2}{*}{$\begin{array}{l}\text { End of } \\
\text { operation }\end{array}$} \\
\hline & & & & Begin & End & \\
\hline Group I & $21 \pm 2$ & $43 \pm 5$ & $67 \pm 7$ & $71 \pm 7$ & $74 \pm 6$ & $78 \pm 7$ \\
\hline Group II & $29^{*} \pm 3$ & $60 \pm 6$ & $92 \pm 8$ & $100 \pm ?$ & $108 \pm 7$ & $12 i \pm 9$ \\
\hline Group III & $30^{*} \pm 3$ & $121 \pm 6$ & $130 \pm 8$ & $132 \pm 5$ & $139=7$ & $144 \pm 6$ \\
\hline
\end{tabular}

${ }^{*} p<0.05$, analysis of variance with Bonferoni modification when compared to Group I values at the same tirne.

in Salt Lake City. Since the distribution of patients ${ }^{+}$ demographic information (Table I), preoperative haemodynamics (Table 1) and results obtained were similar in the two hospitals, data for the same group were combined for statistical analysis. The ages, weights and preoperative heart rates, right atrial, pulmonary artery capillary wedge and systemic arterial blood pressures and cardiac outputs of the patients in the three groups were similar. All but two patients (one each in Groups I and II) were routinely taking one or two vasodilators. Only six patients (two in each group) were taking hydrochlorothiazide.

Patients in Group I required an average of $21 \pm$ $6 \mu \mathrm{g} \cdot \mathrm{kg}^{-1}$ of fentanyl for unconsciousness while those in Groups II and III needed $29 \pm 6$ and $30 \pm 6$ $\mu \mathrm{g} \cdot \mathrm{kg}^{-1}$, respectively (Table II). Differences in the induction doses of fentanyl and times of induction (Table III) between Group I and Groups II and III were statistically significant. The protocol dictated that patients in Group III receive more fentanyl during the immediate postinduction period than patients in Groups I and II. Thus, at the beginning of the operation (incision) the three groups had received markedly different doses of fentanyl, Table II. From incision until the end of operation, patients in Groups I and III received an average of $35 \pm 6$ and $23 \pm 6 \mu \mathrm{g} \cdot \mathrm{kg}^{-1}$ of aditional fentanyl respec-

TABLE III Responses to anaesthetic induction with fentanyl

\begin{tabular}{|c|c|c|c|c|c|}
\hline & \multirow{2}{*}{$\begin{array}{l}\text { Induction } \\
\text { time } \\
\text { (Minutes, } \\
\text { Mean } \pm S D \text { ) }\end{array}$} & \multirow[b]{2}{*}{ None } & \multicolumn{2}{|c|}{ Rigidity (\%) } & \multirow[b]{2}{*}{ Total } \\
\hline & & & Mild & Severe & \\
\hline Group I & $3.4 \pm 0.4$ & $90^{*}$ & $10^{*}$ & 0 & $10^{*}$ \\
\hline Group II & $4.9 \dagger \pm 0.5$ & 20 & 70 & 5 & 75 \\
\hline Group III & $5.0 \dagger=0.6$ & $95^{*}$ & $5^{*}$ & 0 & $5^{*}$ \\
\hline
\end{tabular}

${ }_{\mathrm{p}}<0.01$, Chi-square test when compared to Group II.

$t_{p}<0.025$, stucients unpaired t-test when compared to Group $\mathrm{I}$. 
tively, whereas patients in Group II received an additional $61 \pm 7 \mu \mathrm{g} \cdot \mathrm{kg}^{-1}$ of fentanyl to maintain arterial blood pressures similar to control values (Table II). The differences in additional fentanyl between Groups I and II and II and III were statistically significant ( $p<0.025$, analysis of variance), whereas the difference between Groups I and II was almost, but not quite, statistically significant $(\mathrm{p}>$ $0.05)$.

Muscle rigidity occurred in ten per cent of patients in Group I, five per cent in Group III and 75 per cent of patients in Group II (Table III). Differences between Group II and the other groups were highly statistically significant $(p<0.01$, Chi-square test). There were no significant differences in rigidity between Groups I and III. In only one patient (Group II) was rigidity severe enough to prevent positive pressure ventilation prior to succinylcholine administration.

Induction of araesthesia with fentanyl produced small decreases in systolic arterial blood pressures in all groups which were transient and back to control values following tracheal intubation and at the time of incision. All other measured cardiovascular variables were similar to control values in all groups during anaesthetic induction, following tracheal intubation and at the time of incision. Cardiac output remained unchanged throughout the study period in all groups. While patients in Groups I and III experienced no significant changes in systolic or diastolic arterial blood pressures after chest wall incision, stemotomy and sternal spread, patients in Group II sustained significant increases in both these variables (in spite of additional fentanyl) five and ten minutes after sternal spread. Systolic arterial blood pressure was increased more than 20 per cent of control (preangesthetic) values in 40 per cent of patients in Group II following sternotomy and in 80 per cent of this group after stemal spread (Table IV). In contrasi, only ten per cent of patients in Groups I and III had similar increases of systolic arterial blood pressure during these periods.

Phentolamine and sodium nitroprusside were never required to control arterial blood pressure in Group I and were required in only ten per cent of patients in Group III (Table V). $\mathrm{N}_{2} \mathrm{O}$ was only needed in 20 per cent of patients in Groups I and III after cardiopulmonary bypass (Table $\mathrm{V}$ ). In contrast, phentolamine, nitroprusside and $\mathrm{N}_{2} \mathrm{O}$ were
TABLE IV Per cent of patients with increase in systolic arterial blood pressure greater than $20 \%$ of control values during stressful stimulation

\begin{tabular}{llrll}
\hline & $\begin{array}{l}\text { Tracheal } \\
\text { inubation }\end{array}$ & Incision & Sternotomy & Sternat spread \\
\hline Group I & 0 & 0 & 10 & 10 \\
Group II & 0 & 10 & 40 & $80^{*}$ \\
Group III & 0 & 0 & 10 & 10 \\
\hline
\end{tabular}

$*_{p}<0.001$, Chi-square test when compared to all other groups at the same time.

TABLE $\mathrm{V}$ Per cent of patients requiring supplementation with phentolamine, $\mathrm{N}_{2} \mathrm{O}$ and nitropnusside

\begin{tabular}{lcclll}
\hline & \multicolumn{3}{c}{ Phentamine } & & \\
\cline { 2 - 4 } & $\begin{array}{l}\text { Before } \\
\text { bypass }\end{array}$ & $\begin{array}{l}\text { During } \\
\text { bypass }\end{array}$ & $\begin{array}{l}\mathrm{N}_{2} \mathrm{O} \\
\text { afler } \\
\text { bypass }\end{array}$ & $\begin{array}{l}\text { Nitroprusside } \\
\text { afler bypass }\end{array}$ \\
\hline Group I & 0 & 0 & 20 & 0 \\
Group II & $40^{*}$ & $50^{*}$ & $60^{*}$ & $40^{*}$ \\
Group III & 10 & 0 & 20 & 10 \\
\hline
\end{tabular}

${ }^{*} p<0.01$, Chi-square test when compared to Group I at the same time.

often needed for contral of hypertension before, during and after bypass in Group II (Table V).

All patients were conscjous within nine hours of the end of operation; * however, patients in Group III required a significantly longer period for recovery of consciousness than patients in Groups I and II (Table VI). Mean time for fulfillment of the criteria for tracheal extubation was similar in Groups I and II but significantly longer in Group 111. All of the 40 patients in Groups I and II could have been extubated, according to our criteria for extubation, by the end of the tenth postoperative hour. In contrast, 65 per cent of patients in Group III did not fulfill the criteria for intubation after the tenth postoperative hour. The differences between Group III and Groups I and II with respect to recovery of consciousness and time to extubation were statistically significant. All patients were successfully extubated by the morning following the day of surgery. When interviewed 48 hours postoperatively, no patient in any group remembered laryngo-

*The duration of the operations in the five groups was not significantly different and averaged $5.7 \pm 1.3$ hours. 
TABLE VI Recovery times (Mean \pm SD)

\begin{tabular}{|c|c|c|c|}
\hline & $\begin{array}{l}\text { Time do } \\
\text { consciousness } \\
\text { (hrs) }\end{array}$ & $\begin{array}{l}\text { Ready for } \\
\text { exubation* } \\
\text { (hrs) }\end{array}$ & $\begin{array}{l}\text { Patients not ready } \\
\text { for extubation } \\
10 \text { hours after } \\
\text { operation (\%) }\end{array}$ \\
\hline Group I & $\begin{array}{l}2.3(n=20) \\
\pm 1.5\end{array}$ & $\begin{array}{l}5.1(n=20) \\
\pm 1.6\end{array}$ & 0 \\
\hline Group II & $\begin{array}{l}2.2(\mathrm{n}=20) \\
\pm 1.3\end{array}$ & $\begin{array}{l}4.7(n=20) \\
\pm 1.7\end{array}$ & 0 \\
\hline Group III & $\begin{array}{l}6.6 \dagger(n=20) \\
\pm 2.5\end{array}$ & $\begin{array}{l}7.5 \dagger(n=7) \\
=1.6\end{array}$ & $65 t$ \\
\hline
\end{tabular}

*Data in this column are from patients who were considered ready for endotracheal extubation before the 11 th postoperative hour. Only seven of the 20 patients in group III fulfilled the criteria for exubation by the 11 th postoperative hour. The recording $(7.5 \pm 1.6 \mathrm{hrs})$ represents the mean time these seven patients took to fulfill the criteria for extubation.

tp $<0.05$, analysis of variance when compared to Groups I and 11 .

$\$ p<0.025$, Chi-square test when compared to Groups I or II.

scopy, tracheal intubation, or any aspect of the operative procedure.

\section{Discussion}

Numerous investigators have reported significant incidences of chest wall rigidity, tachycardia, hypertension and awareness during high dose fentanyl anaesthesia for coronary artery surgery. ${ }^{7-13}$ These undesirable side effects were not found in the original studies with anaesthetic doses of fentanyl in patients undergoing mitral valvular or coronary artery bypass grafting operations. ${ }^{1,2}$ However, in the original studies fentanyl was given to an "anaesthetic effect" (unconsciousness) before paralysis with a muscle relaxant and additional supplements of the opioid were given throughout the remainder of the operation in response to signs of light anaesthesia (increases in arterial blood pressure, sweating, tearing, pupillary dilation, etc.). Later investigations by our group suggested that the dose of fentanyl producing unconsciousness (the sleep dose) should be administered again after tracheal intubation and before incision to insure adequate anaesthesia and haemodynamic stability during the initial phases of operation. ${ }^{14,15}$ Furthermore, these studies demonstrated that supplementation with additional fentanyl was often required to maintain haemodynamic stability in spite of large initial doses of the drug. Subsequent studies by other investigators most often report the use of a pre-selected or fixed dose of fentanyl $(30,70,100$ or $150 \mu \mathrm{g} \cdot \mathrm{kg}^{-1}$ ) usually given as a single bolus without reference to a demonstrated "anaesthetic effect" and usually shortly before or at the same time a large dose of pancuronium or another muscle relaxant is administered for paralysis..$^{3-6,9-13}$ Furthermore, following anaesthetic induction in these studies, additional fentanyl is rarely used for supplementation during the remainder of the anaesthetic and operation.

We believe the pre-selected "fixed dose," single bolus technique of giving anaesthetic doses of fentanyl (or any other opioid) without reference to an observable anaesthetic effect prior to muscle relaxation and tracheal intubation is inappropriate because it assumes that all patients will have similar anaesthetic requirements and pharmacokinetic profiles. We believe the results of this study confirm our beliefs.

The data demonstrate that patients with coronary artery disease and a history of more than occasional smoking and alcoholic and caffeine consumption require more fentanyl for unconsciousness and anaesthesta throughout operation than patients not exposed to these agents. The data also indicate that patients with significant smoking, caffeine and alcoholic intake historics nced more pancuronium prior to anaesthetic induction to minimize fentanyl induced chest wall rigidity. Finally, our findings indicate that larger doses of fentanyl prior to surgical stimulation and adequate supplementation with additional fentanyl during operation can minimize hypertension and the need for other anaesthetics and vasodilators, but the cost of this practice is a slower recovery after operation. These results suggest the habits (smoking, caffeine and alcohol intake histories) of patients may affect the incidence of anaesthetic problems with fentanyl-oxygen anaesthesia but that modifications in technique can minimize or eliminate these problems.

The reason why smoking and consumption of alcohol and caffeine increases requirements for fentanyl is unknown. It is possible that the chronic use of central nervous system stimulants such as caffeine and nicotine and depressants such as alcohol induce changes in central nervous membrane structure and consequently function. ${ }^{16-18}$ Chin and Goldstein ${ }^{16}$ have demonstrated altered fluidity. in regions of red blood cell and brain membranes where phospholipid head groups are 
exposed to low concentraions of ethanol. Numerous investigations have shown that the chronic use of alcohol induces cross tolerance for inhalation anaes. thetics, tranquillizers, sedative/hypnotics, narcotics and other central nervous system stimulants and depressants. ${ }^{19-22}$ Evidence has been presented in some of these studies that the development of cellular tolerance to ethanol and at least some other central nervous system depressants and stimulants is also related to changes in membrane structure and function. ${ }^{16,18.22}$ Although none of our patients admitted to or could be categorized (by history, physical examination or preoperative laboratory studies) as a chronic alcoholic by modern definitions of the disease, ${ }^{17}$ alcoholics are known to require more opioids (fentanyl) ${ }^{19}$ and potent inhalation agents ${ }^{20,21}$ for an adequate depth of anesthesia than non-alcoholics. Whether similar, less marked or any changes occur in patients that are frequent consumers of alcohol but not "chronic alcoholics" is not, to our knowledge, known. Furthermore, what contribution, if any, caffeine intake and smoking provide to the development of tolerance to alcohol and cross tolerance to other central nervous system stimulants and depressants is not clear and cannot be answered by review of our data.

Other possible explanations for increased fentanyl requirements in Groups II and III in this study could be an increased volume of distribution and/or impaired metabolism of fentanyl or increased intracellular plasma or total body fluid volume. While there are data demonstrating that ethanol-treated animals develop increases in intracellular, plasma and total body fluid volume, ${ }^{21}$ there is no evidence that a difference in any of these variables existed in our three groups. Similarly, a recent study showing that patients with confirmed alcoholic cirrhosis exhibit no difference in the volume of distribution of fentanyl or its metabolic handling suggests that differences in these variables are also unlikely explanations for our findings. ${ }^{23}$

Rigidity was only observed in two patients in Group I in this study. In contrast, it was noted in 80 per cent of patients in Group II, who received the same pretreatment dose of pancuronium $(1.0 \mathrm{mg} /$ $70 \mathrm{~kg}$ ). When pre-induction pancuronium was increased to $1.5 \mathrm{mg} / 70 \mathrm{~kg}$ (Group III), the incidence of rigidity was markedly reduced. One explanation for this phenomenon may be related to the higher doses of fentanyl required for unconsciousness in patients in Groups II and III than in Group I. Experiments in rats indicate that the incidence of rigidity increases in direct proportion to the dose of fentanyl. ${ }^{24}$ If this is true in man, the incidence of rigidity during induction should have been similar in Groups II and III and greater than in Group I (assuming similar sensitivity of all groups to fentanyl induced rigidity). That Group III had a significantly lower incidence of rigidity than Group II could be due to the larger dose of pancuronium these patients received just prior to induction of anaesthesia.

Another explanation for the differences in rigidity observed in the study could be related to a reduced sensitivity of patients in Groups II and III or an increased sensitivity of patients in Group I to nonpolarizing muscle relaxants. We are unaware of studies evaluating the effects of smoking, alcohol and caffeine on the effectiveness of non-depolarizing muscle relaxants; however, Katz et al. ${ }^{25}$ found that patients in London experienced significantly less depression of both the magnitude and duration of action in the twitch response of the adductor pollicis muscle to supramaximal stimulation of the ulnar nerve following d-tubocurarine $\left(0.1 \mathrm{mg} \cdot \mathrm{kg}^{-1}\right)$ than patients in New York. Others have found that patient responses to muscle relaxants in California are similar to those in New York. ${ }^{26}$ The mechanism for the difference in sensitivity of these different populations to non-depolarizing relaxants was not explained, but it was thought not to be related to environment because Americans living in London responded similarly to New Yorkers. ${ }^{25}$ Unfortunately, careful histories of the smoking and alcoholic and caffeine consumption habits of patients in those studies were not reported and probably not taken.

Legitimate criticisms of this study include its performance at two different institutions over a long period of time, the use of unblinded as well as blinded investigators, the difficulty of controlling for changes in surgical technique and/or surgical practice that could affect outcome, and the relevance of these findings in view of current medical therapy of patients with coronary artery disease which often includes calcium channel and beta blocking agents. While these are potentially serious criticisms, we feel they don't limit interpretation of our results because: the study was performed simultaneously and patient selection, distribution 
and number was similar in the two institutions; the methodology (inclusion and exclusion criteria) was precisely defined and rigidly adhered to in order to produce distinctly different patient groups with regad to habits and anaesthetic management; the study was carefully designed to eliminate patients whose cardiac (calcium channel and beta-blocking drugs) and other medications (barbiturates and benzodiazepines) might, by a hepatic enzyme inducing capacity or other influences on anaesthetic (opioid) action, mimic, diminish or confuse changes in responses produced by different habits; and, while unblinded investigators were necessary for decisions regarding patient eligibility and strict adherence to study protocol, the crucial determinations (when the patients became unconscious, required additional fentanyl, required a supplement, became conscious after operation, and fulfilled the criteria for extubation) were made by clinician-investigators who were not only blinded to whether a patient was or was not in the study but also to what group he or she was assigned. Our rigid protocol and changing patterns in cardiac medications resulted in the ineligibility of most patients approached and necessitated that the study continue for almost three years. In spite of this handicap, few important changes in surgical technique occurred and there were no significant differences in the duration of operations at the beginning of the study or its termination. Likewise, there were also no differences in morbidity (no patient in the study suffered a perioperative myocardial infarction or sustained an arrhythmia requiring intra- or postoperative medical management) or mortality (all patients survived the operation and were discharged from the hospital) at the two institutions or at the study's inception and conclusion. Finally, while it is clear that the use of beta adrenergic blocking drugs, ${ }^{14}$ benzodiazepines, ${ }^{27,28}$ barbiturates, ${ }^{29}$ and perhaps numerous other compounds (including calcium channel blockers) may modify or alter patient responses during anaesthesia with large doses of opioids, it is unlikely that any or all of these agents would totally negate or antagonize the influence of patient habits.

In conclusion, our results in this study suggest that habits of patients, particularly a significant history of smoking and caffeine and alcoholic intake, may affect the incidence of anaesthetic problems with fentanyl-oxygen anaesthesia, but that modifications in technique can minimize or eliminate these problems.

\section{Acknowledgements}

The authors wish to acknowledge the untiring editorial and secretarial assistance of Ms. Karen Bell and the patience, assistance and devotion of Michael Boscoe MD, Norbet de Bruijn MD, James Sederberg MD, and Parsad Reddy MD, without whose efforts this manuscript would not have been possible.

\section{References}

1 Stanley $T H$, Webster $L R$. Anesthetic requirements and cardiovascular effects of fentanyl-oxygen and fentanyl-diazepam-oxygen anesthesia in man. Anesth Analg 1978; 57: 411-6.

2 Lunn JK, Stanley TH, Eisele J, Webster LR, Woodward $A$. High dose fentanyl anesthesia for coronary artery surgery: Plasma fentanyl concentrations and influence of nitrous oxide on cardiovascular responses. Anesth Analg 1979; 58: 390-5.

3 Bovill JG, Sebel PS. Pharmacokinetics of high. dose fentanyl. A study of patients undergoing cardiac surgery. Br J Anaesth 1980; 52: 795-801.

4 Sebel PS, Bovill JG, Wauquier A, Rog P. Effects of high dose fentanyl anesthesia on the electroencephalogram. Anesthesiology 1981; 55: 203-11.

5 Sebel PS, Bovill JG, Boekhorst RAA, Rog $P$. Cardiovascular effects of high dose fentanyl anaesthesia. Acta Anesthesiol Scand 1982; 26: 308-15.

6 Wynands JE. Anesthetic consideration for coronary artery surgery. Cleve Clin Quarterly 1981; 48 : $86-92$.

7 Editorial: High-dose fentanyl. Lancet 1979; 1 : 81-2.

8 Waller J, Hug C, Nagle DM, Craver JM. Hemodynamic changes during fentanyl-oxygen anesthesia for aortocoronary bypass operation. Anesthesiology 1981; 55: 212-7.

9 Hill AB, Nahnwold ML, de Rosayro AM, Knight $P R$, Jones RM, Bolles RE. Prevention of rigidity during fentanyl-oxygen induction of anesthesia. Aneschesiology 1981; 55: 452-4.

10 Wynands JE, rownsend GE, Wong $P$, Whalley $D G$, Cormbatore BS, Patel YC. Blood pressure response and plasma fentanyl concentrations during high and very high dose fentanyl anes- 
thesia for coronary artery surgery. Anesth Analg 1983; 62: 661-5.

11 Quinton L, Whalley DG, Wynands JE, Morin JE, Mayer $R$. Oxygen-high dose fentanyl-dmperidol anesthesia for aortocoronary bypass surgery. Anesth Analg 1981; 60: 412-6.

12 Hilgenberg JC. Intraoperativc awarencss during high-dose fentanyl oxygen anesthesia. Anesthesiology 1981; 54: 341-3.

13 Mummaneni $N$, Rao TLK, Montoya A. Aware ness and recall with high-dose fentanyl-oxygen anesthesia. Anesth Analg 1980; 59: 948-9.

14 de Lange S, Boscoe MJ, Stanley TH. Comparison of sufentanil- $\mathrm{O}_{2}$ and fentanyl- $\mathrm{O}_{2}$ for coronary artery surgery. Anesthesiology 1982; 56: 112-8.

15 Stanley $T H$. High dose narcotic anesthesia. Seminars in Anesthesia 1982; 1: 21-32.

16 Chin JH. Goldstein DB. Effects of low concentrations of ethanol on the fluidity of spin-labellcd erythrocyte and brain membranes. Mole Pharmacol 1977; 13: 435-42.

17 Bruce DL. Alcoholism and anesthesia. Anesth Analg 1983; 62: 84-96.

18 Littleton JM. Cellular tolerance to ethanol as membrane adaptation: A review. Br J Alc Alcoholism 1979; 14: 23-36.

19 Tamnisto $T$, Tigersted $/$. The need for fentanyl supplementation of $\mathrm{N}_{2} \mathrm{O}-\mathrm{O}_{2}$ relaxant anesthesia in chronic alcoholics. Acta Anaesthesiol Scand 1977; 21: 216-21.

20 Johnstone $R E$, Kulp RA, Smith TC. Effects of acute and chronic ethanol administration on isoflurane requirements in mice. Anesth Analg 1975; 54: 277-81.

21 Adriari J, Morton RC. Drug dependence: important considerations from the anesthesiologist's viewpoint. Anesth Analg 1968; 47: 472-81.

22 Seeman $P$. The membrane actions of anesthetics and tranquilizers. Pharm Rev 1972; 24: 583-655.

23 Haberer JP, Schaeffler P, Couderc E. Duvaldestin $P$. Fentanyl pharmacokinetics in anacsthetized patients with cirrhosis. Br J Anaesth 1982; 54: 1267-70.

24 Stanley TH, Leysen J, Niemegeers CJE. The influence of diazcpam and droperidol in CNS receptor binding. Anesthesiology 1983; 53: S33.

25 Katz RL. Norman H, Seed RF. Comad L. A comparison of the effects of suxamethonium and tubocurarine in patients in London and New York. Br J Anaesth 1969; 41: 1041-7.
26 Watts $L F$, Lebowitz $M$, Dillon $J B$. The effects of ventilation on the action of tubocurarine and gallamine. Br J Anaesth 1967; 39: 840-5.

27 Tomichek RC, Rosow CE, Schneider RC. Moss $J$, Philbin DM. Cardiovascular effects of diazepam-fentanyl anesthesia in patients with coronary antery disease. Anesth Analg 1982; 61: 217-8.

28 Reves JG, Kissin I, Fourmir SE. Additive negative inotropic effect of a combination of diazepam and fentanyl. Anesthesiology 1983; 59: A326.

29 Stoelting $R K$. Influence of barbiturate anesthetic induction on circulatory responses to morphine. Anesth Analg 1977; 56: 615-7.

Résumé

Dans cette êtude, nous arons mesuré et comparé les besoins anesthésiques, l'incidence de rigidité de la cage thoracique el d' hypertension per-opératoire et le temps de recouvrance de l'anesthésie après des hautes doses de fentanyl pour un pontage aorto-coronarien chez des individus avec ou sans histoire de tabagisme, prise d'alcool ou consommation de caféine (groupe témoin). Les patients du groupe témoin nécessitèrent moins de fentastyl pour l' induction et le maintien de l'anesthésie. Il y eût également moins de rigidité thoracique et moins $d^{\prime}$ hypertension per-opératoire chez les patients de ce groupe. Pour les patients du groupe habirué au tabac, à l'alcool et à la cafsine un pré-traitement à dose plus élevée de pancuronium $(1.5 \mathrm{vs} .1 .0 \mathrm{mg} / 70 \mathrm{~kg})$ avant l'induction de l'anesthésie et l'augmentation des doses de fentany? ( $3 \times$ vs $I \times$ la dose d"induction) avant $l$ 'incision ont ramene $l$ ' incidence de rigidite thoracique et d' hypertension per-opératoire au niveau du groupe témoin. Notre étude suggère que certaines habitudes de ta population peuvent augmenter les effets indésirables des hautes doses de fentanyl et que la modification de ta technique anesthésique peut minimiser ou éliminer ces problèmes. 